\title{
Testing, infection and complication rates of COVID-19 among people with a recent history of homelessness in Ontario, Canada: a retrospective cohort study
}

\author{
Lucie Richard MA, Richard Booth PhD, Jennifer Rayner PhD, Kristin K. Clemens MD MSc, \\ Cheryl Forchuk PhD, Salimah Z. Shariff $\mathrm{PhD}$
}

\section{Abstract}

Background: People with a recent history of homelessness are believed to be at high risk of infection with severe acute respiratory syndrome coronavirus 2 (SARS-CoV-2) and, when infected, complications of coronavirus disease 2019 (COVID-19). We describe and compare testing for SARS-CoV-2, test positivity and hospital admission, receipt of intensive care and mortality rates related to COVID-19 for people with a recent history of homelessness versus community-dwelling people as of July $31,2020$.

Methods: We conducted a population-based retrospective cohort study in Ontario, Canada, between Jan. 23 and July 31, 2020, using linked health administrative data among people who either had a recent history of homelessness or were dwelling in the community. People were included if they were eligible for provincial health care coverage and not living in an institutionalized facility on Jan. 23, 2020. We examined testing for SARS-CoV-2, test positivity and complication outcomes of COVID-19 (hospital admission, admission to intensive care and death) within 21 days of a positive test result. Extended multivariable Cox proportional hazard models were used to estimate adjusted hazard ratios (HRs) in 3 time periods: preshutdown (Jan. 23-Mar. 13), peak (Mar. 14-June 16) and reopening (June 17-July 31).

Results: People with a recent history of homelessness ( $n=29407)$ were more likely to be tested for SARS-CoV-2 in all 3 periods compared with community-dwelling people $(n=14494301)$ (preshutdown adjusted HR 1.61, 95\% confidence interval [CI] 1.22-2.11; peak adjusted HR 2.95, 95\% Cl 2.88-3.03; reopening adjusted HR 1.45, 95\% Cl 1.39-1.51). They were also more likely to have a positive test result (peak adjusted $\mathrm{HR} 3.66,95 \% \mathrm{Cl} 3.22-4.16$; reopening adjusted $\mathrm{HR} 1.76,95 \% \mathrm{Cl} 1.15-2.71$ ). In the peak period, people with a recent history of homelessness were over 20 times more likely to be admitted to hospital for COVID-19 (adjusted HR 20.35, 95\% Cl 16.23-25.53), over 10 times more likely to require intensive care for COVID-19 (adjusted HR $10.20,95 \% \mathrm{Cl} 5.81-17.93$ ) and over 5 times more likely to die within 21 days of their first positive test result (adjusted HR $5.73,95 \%$ Cl 3.01-10.91).

Interpretation: In Ontario, people with a recent history of homelessness were significantly more likely to be tested for SARS-CoV-2, to have a positive test result, to be admitted to hospital for COVID-19, to receive intensive care for COVID-19 and to die of COVID-19 compared with community-dwelling people. People with a recent history of homelessness should continue to be considered particularly vulnerable to SARS-CoV-2 infection and its complications.

\footnotetext{
T $\mathrm{n}$ the early months of the coronavirus disease 2019 (COVID-19) pandemic, there was substantial discourse about its estimated impact on people experiencing homelessness. ${ }^{1-6}$ This population is believed to be at increased risk of infection, because of high population density in shelters and other precarious housing, ${ }^{3}$ and negative outcomes following infection. ${ }^{7}$ Indeed, by May 2020, numerous emergency shelters in North American cities had reported COVID-19 outbreaks, ${ }^{8-10}$ prompting distancing countermeasures in many Ontario cities (e.g., temporary housing in hotels). ${ }^{11-19}$ Despite this, to date there is little
}

Competing interests: Outside of the submitted work, Kristin Clemens has received a research award funded in part by AstraZeneca, she has attended Merck-sponsored conferences and she has received personal fees to deliver continuing medical education talks from Sutherland Global Services Canada ULC and the Canadian Medical and Surgical Knowledge Translation Research Group. No other competing interests were declared.

This article has been peer reviewed.

Correspondence to: Lucie Richard, lucie.richard@ices.on.ca

CMAJ Open 2021. DOI:10.9778/cmajo.20200287 
understanding of the spread of severe acute respiratory syndrome coronavirus 2 (SARS-CoV-2) among people who are homeless in Canada, in part because capturing the true number of people experiencing homelessness at a given time is difficult. ${ }^{20}$ There is also no information about this population's risk for SARS-CoV-2 infection and associated complications of COVID-19 relative to the general, communitydwelling population.

Leveraging a validated case definition for homelessness ${ }^{21}$ and population-level health administrative databases, we aimed to describe rates of SARS-CoV-2 testing, test positivity and hospital admission, intensive care receipt and mortality related to COVID-19 among people with a recent history of homelessness and to compare these rates with those for the community-dwelling population in Ontario, Canada.

\section{Methods}

\section{Study design and setting}

We conducted a retrospective population-based cohort study in Ontario using health administrative data. Databases were linked using unique encoded identifiers and analyzed at ICES. ${ }^{22}$ ICES is a prescribed entity under section 45 of Ontario's Personal Health Information Protection Act, which authorizes ICES to collect personal health information, without consent, for the purpose of analysis or compiling statistical information with respect to the management of, evaluation or monitoring of, the allocation of resources to or planning for all or part of the health system. This study follows the Reporting of Studies Conducted Using Observational Routinely Collected Data (RECORD) reporting guidelines. ${ }^{23}$

\section{Participants}

All participants were followed from an index date of Jan. 23, 2020, the date of the first known COVID-19 case in Ontario, ${ }^{24}$ until July 31, 2020, the latest date for which complete data were available at the time of analysis. Participants comprised 2 groups. The community-dwelling group included all Ontario residents eligible for Ontario Health Insurance Plan (OHIP) coverage who were not living in an institutionalized facility (i.e., not living in long-term care, admitted to hospital or receiving continuing care services in hospital) and not identified as a person with a recent history of homelessness.

We identified a person with a recent history of homelessness as anyone eligible for Ontario health coverage who was not living in an institutionalized facility and who met the case definition of recent history of homelessness (any indication of homelessness in the Canadian Institute for Health Information [CIHI] Discharge Abstract Database [DAD], the CIHI Same Day Surgery [SDS] database, the National Ambulatory Care Reporting System [NACRS], the Ontario Mental Health Reporting System [OMHRS] and the ICES PSTLYEAR data sets; Appendix 1, Supplemental Table S1, available at www.cmajopen.ca/content/9/1/E1/suppl/DC1, lists specific indicators) during a health care encounter between Oct. 1, 2018, and July 31, 2020. The selected case definition was adopted from a recent validation study; ${ }^{21}$ we extended the case definition a priori to July 31, 2020, to more comprehensively capture people identified as homeless during the pandemic. In the validation, the sensitivity of the selected algorithm was $33.2 \%$ and the specificity was over $99.9 \% ;{ }^{21}$ however, reporting of homelessness in CIHI-administered databases using International Statistical Classification of Diseases and Related Health Problems, 10th Revision (ICD-10) codes Z59.0 and Z59.1 has since become mandatory. ${ }^{25} \mathrm{We}$ anticipate this change in coding practice will have increased the sensitivity of the case definition.

\section{Data sources}

Data sources used to define participants, outcomes and covariates included the following: the DAD and the SDS database; the NACRS; the OMHRS; the Ontario Laboratories Information System; the ICES Registered Persons Database demographic and postal year data sets; the OHIP claims database; the Immigration, Refugee and Citizenship Canada Permanent Resident Database; the Ontario Drug Benefit (ODB) Database; and several ICESderived population-surveillance data sets, including the Chronic Obstructive Pulmonary Disease Database, ${ }^{26}$ the Ontario Asthma Database, ${ }^{27}$ the Ontario Diabetes Database, ${ }^{28}$ the Congestive Heart Failure Database ${ }^{29}$ and the Ontario Hypertension Database. ${ }^{30}$ These databases are further described in Appendix 1, Supplemental Tables S1 and S2.

\section{Outcome measure}

Our primary outcome was the receipt of a SARS-CoV-2 test, recorded in the Ontario Laboratories Information System or during a DAD or NACRS encounter with a diagnosis indicating laboratory-confirmed SARS-CoV-2 (ICD-10 code U07.1), suspected COVID-19 (U07.2) or a negative laboratory test result (Z03.8). Because the latter 2 diagnoses do not necessarily indicate receipt of a SARS-CoV-2 laboratory test, we considered only encounters with these codes after Mar. 17, when Ontario declared a state of emergency. ${ }^{31} \mathrm{CIHI}$ mandates the use of code Z03.8 when COVID-19 is ruled out by laboratory testing and code U07.2 when COVID-19 is suspected but laboratory results are inconclusive or unavailable. ${ }^{32}$ After Mar. 17, symptomatic individuals presenting to hospital were likely to receive a SARS-CoV-2 test.

Results of tests for SARS-CoV-2 were categorized as positive or nonpositive, with indeterminate and pending results considered nonpositive. Cancelled or rejected tests were not considered. Where there were multiple tests or hospital encounters, a person was deemed to have a positive result where any test or hospital encounter indicated positivity. The first test date was assigned as the outcome date, unless a nonpositive test result was superseded by a following positive test result or hospital encounter, in which case the date of the first positive result was assigned.

Our secondary outcomes were hospital admission for confirmed COVID-19 (U07.1), hospital admission requiring intensive care for confirmed COVID-19 and death within 21 days of first evidence of SARS-CoV-2 test positivity. 


\section{Other covariates}

We obtained participants' demographic characteristics as of Jan. 23, 2020, including age, sex, neighbourhood income quintile, level of urbanicity and immigrant status. As people with a recent history of homelessness are known to have more comorbidities, ${ }^{7,33}$ we measured asthma, chronic obstructive pulmonary disorder, diabetes, congestive heart failure and hypertension. Finally, we obtained the number of primary health care encounters in the previous year, as a proxy for propensity to seek SARS-CoV-2 testing, and receipt of health care related to mental health in the previous year, as an indicator of potential barriers to following pandemic-related recommendations. ${ }^{3,33}$ Complete variable definitions are available in Appendix 1, Supplemental Table S3.

\section{Statistical analysis}

We conducted all analyses using SAS version 9.4. We compared covariates using one-way analysis of variance, KruskalWallis, Cochran-Armitage or $\chi^{2}$ tests, as appropriate. As our combined groups include nearly all Ontarians, we also reported standardized differences, which assess differences between group means as a percentage of the pooled standard deviation; a difference of $10 \%$ or more was considered significant. ${ }^{34} \mathrm{We}$ calculated outcome rates per 100 person-years for each outcome.
As testing policies varied during follow-up, we used extended multivariable Cox proportional hazards models ${ }^{35}$ to estimate the hazard ratio during consecutive observation periods meeting the proportional hazards assumption. Hazard ratios (HRs) and 95\% confidence intervals (CIs) were estimated using Heaviside functions. Censoring events included entry into long-term care and death (except for the mortality outcome, where death was an outcome event). Covariates for adjusted models were selected on the basis of substantial differences observed between groups and associations with outcomes (risk for testing, infection or complications after infection). Model results are presented as unadjusted and adjusted HRs, with accompanying $95 \%$ CIs. In all outputs, small cells (fewer than 6) were suppressed to protect patient privacy.

\section{Ethics approval}

The use of data in this project was authorized under section 45 of Ontario's Personal Health Information Protection Act, which does not require review by a research ethics board.

\section{Results}

We identified 29407 people with a recent history of homelessness and 14494301 community-dwelling people (Figure 1). Compared with the latter group, people with a recent history

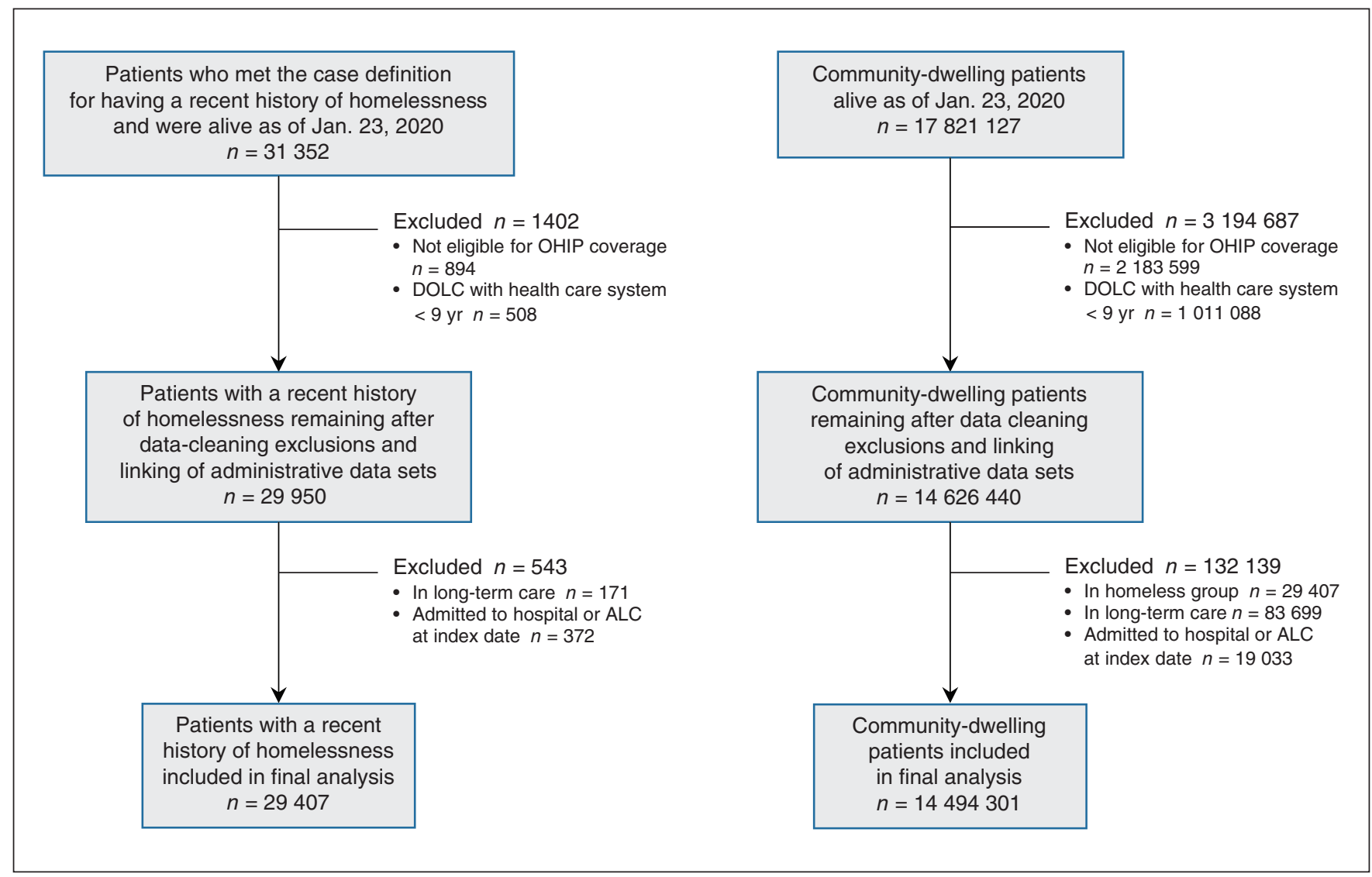

Figure 1: Diagram illustrating how the study cohort was built. Note: ALC = alternate level of care (a clinical designation identifying patients in Ontario hospitals who no longer require the intensity of resources provided in their current acute care setting and are waiting for discharge to an appropriate destination), DOLC = date of last contact, OHIP = Ontario Health Insurance Plan. 
of homelessness were more likely to be 25-39 years old (35.8\% v. $19.7 \%)$ or $40-64$ years old ( $40.5 \%$ v. $34.1 \%)$, to be male $(68.0 \%$ v. $49.2 \%)$ and to reside in the lowest income neighbourhoods $(43.3 \%$ v. $18.8 \%)$ or small to medium census metropolitan areas (34.3\% v. 27.3\%) (Table 1). Conversely, people with a recent history of homelessness were less likely to have immigrated to Canada within the past 10 years $(1.7 \%$ v. $4.3 \%$ ). People with a recent history of homelessness had a

\begin{tabular}{|c|c|c|c|c|}
\hline \multirow[b]{2}{*}{ Characteristic at index } & \multicolumn{2}{|c|}{ No. $(\%)$ of patients* } & \multirow[b]{2}{*}{$p$ value } & \multirow[b]{2}{*}{$\begin{array}{l}\text { Standardized } \\
\text { difference, \% }\end{array}$} \\
\hline & $\begin{array}{l}\text { People with a } \\
\text { recent history of } \\
\text { homelessness } \\
n=29407\end{array}$ & $\begin{array}{c}\text { Community-dwelling } \\
\text { population } \\
n=14494301\end{array}$ & & \\
\hline \multicolumn{5}{|l|}{ Sociodemographic characteristics } \\
\hline Age, yr, median (IQR) & $38(28-52)$ & $41(23-59)$ & $<0.001$ & 5 \\
\hline Age group, yr & & & \multicolumn{2}{|l|}{$<0.001$} \\
\hline Youth $(<25)$ & 4789 (16.3) & $3996738(27.6)$ & & 28 \\
\hline Young adults (25-39) & $10526(35.8)$ & $2853540(19.7)$ & & 37 \\
\hline Older adults (40-64) & $11898(40.5)$ & $4949782(34.1)$ & & 13 \\
\hline Seniors $(\geq 65)$ & $2194(7.5)$ & $2694241(18.6)$ & & 34 \\
\hline Male & $19994(68.0)$ & 7125208 (49.2) & $<0.001$ & 39 \\
\hline Immigrated within past $10 \mathrm{yr} \dagger$ & $510(1.7)$ & $624664(4.3)$ & $<0.001$ & 15 \\
\hline Immigrated as refugee† & $217(0.7)$ & $106997(0.7)$ & 0.99 & 0 \\
\hline Income quintileł & & & \multicolumn{2}{|l|}{$<0.001$} \\
\hline 1 (lowest) & $12723(43.3)$ & $2724338(18.8)$ & & 55 \\
\hline 2 & $6402(21.8)$ & 2791099 (19.3) & & 6 \\
\hline 3 & $5166(17.6)$ & 3354429 (19.3) & & 14 \\
\hline 4 & $2744(9.3)$ & $2873618(19.8)$ & & 30 \\
\hline 5 (highest) & $2372(8.1)$ & 2750817 (19.0) & & 32 \\
\hline \multicolumn{2}{|l|}{ Level of urbanicity } & & \multicolumn{2}{|l|}{$<0.001$} \\
\hline Large CMA (> 500000 population) & $17018(57.9)$ & $8802812(60.7)$ & & 6 \\
\hline $\begin{array}{l}\text { Small to medium-sized urban centres } \\
\text { (10 000-500 } 000 \text { population }\end{array}$ & $10082(34.3)$ & $3959178(27.3)$ & & 15 \\
\hline Areas with $<10000$ population & $1660(5.6)$ & $1280134(8.8)$ & & 12 \\
\hline Unknown or missing & $647(2.2)$ & $452177(3.1)$ & & 6 \\
\hline \multicolumn{5}{|l|}{ Comorbidities and prior health care use } \\
\hline Asthma or COPD & $7308(24.9)$ & 2344954 (16.2) & $<0.001$ & 22 \\
\hline Diabetes & 3587 (12.2) & $1486515(10.3)$ & $<0.001$ & 6 \\
\hline Congestive heart failure & $820(2.8)$ & $264745(1.8)$ & $<0.001$ & 6 \\
\hline Hypertension & $4833(16.4)$ & $3072844(21.2)$ & $<0.001$ & 12 \\
\hline Care related to mental health in previous year & $21905(74.5)$ & $1909412(13.2)$ & $<0.001$ & 157 \\
\hline Psychotic disorders & $9539(32.4)$ & $171880(1.2)$ & $<0.001$ & 92 \\
\hline Nonpsychotic disorders & $16683(56.7)$ & $1744055(12.0)$ & $<0.001$ & 107 \\
\hline Substance use disorders & $15097(51.3)$ & $204393(1.4)$ & $<0.001$ & 137 \\
\hline $\begin{array}{l}\text { No. of primary care visits in previous year, } \\
\text { median (IQR) }\end{array}$ & $19(6-47)$ & $5(1-11)$ & $<0.001$ & 89 \\
\hline \multicolumn{5}{|c|}{$\begin{array}{l}\text { Note: Cells representing } \leq 5 \text { individuals are suppressed to protect individual privacy. CMA = census metropolitan area, COPD = chronic obstructive pulmonary } \\
\text { disease, IQR = interquartile range. } \\
\text { *Unless indicated otherwise. } \\
\text { †Immigration status defined based on presence of a landing date in the Immigration, Refugees and Citizenship Canada Permanent Resident Database from } \\
2008 \text { to } 2018 \text {. } \\
\text { †Income quintiles at the Dissemination Area level, derived from } 2016 \text { census data. Missing and unknown values were recoded to quintile } 3 .\end{array}$} \\
\hline
\end{tabular}


higher prevalence of respiratory conditions $(24.9 \%$ v. $16.2 \%)$ but a lower prevalence of hypertension (16.4\% v. $21.2 \%)$. They also had had more primary health care visits in the previous year (median 19 visits [interquartile range (IQR) 6-47] v. 5 [IQR 1-11]) and were more likely to have received care related to mental health $(74.5 \%$ v. $13.2 \%)$.

From Jan. 23 to July 31, 2020, 8451 people with a recent history of homelessness (62.10 per 100 person-years) received at least 1 SARS-CoV-2 test, compared with 1266716 communitydwelling people (17.24 per 100 person-years) (Table 2). In unadjusted analyses, we observed 3 periods with distinct testing hazards (the preshutdown period was from Jan. 23 to Mar. 13, the peak period was from Mar. 14 to June 16 and the reopening period was from June 17 to July 31 ). The unadjusted HR of testing was higher among people with a recent history of homelessness in all 3 periods. After we adjusted for age groupings, sex, immigrant status, income quintile, level of urbanicity, presence of comorbidities and outpatient and mental health care usage, HRs for testing remained significant in all periods (preshutdown adjusted HR 1.61, 95\% CI 1.22-2.11; peak adjusted HR 2.95, 95\% CI 2.88-3.03; reopening adjusted HR 1.45, 95\% CI 1.39-1.51).

We identified 274 people with a recent history of homelessness (2.01 per 100 person-years) and 28430 (0.39 per 100 person-years) community-dwelling people with a positive SARS-CoV-2 test result (Table 2). No cases of COVID-19 occurred among people with a recent history of homelessness during the preshutdown period; HRs for this period are thus excluded. People with a recent history of homelessness were more likely to test positive during the peak period (unadjusted HR 5.07, 95\% CI 4.94-5.20) and the reopening period (unadjusted HR 1.05, 95\% CI 1.04-1.07) (Table 3). After adjustment, the HR during both periods remained significant (peak adjusted HR 3.66, 95\% CI 3.22-4.16; reopening adjusted HR 1.76, 95\% CI 1.15-2.71).

We identified 104 people with a recent history of homelessness and 3685 community-dwelling people who were admitted to hospital with COVID-19 (Table 2). No hospital admissions occurred among people with a recent history of homelessness during the preshutdown period. People with a recent history of homelessness were more likely to be admitted to hospital during the peak period (unadjusted HR 65.12 , 95\% CI 53.45-79.34) but not during the reopening period (unadjusted HR 0.51, 95\% CI 0.17-1.59]). After adjustment, the hazard of being admitted to hospital during the peak period was attenuated but still over 20 times that of community-dwelling people (peak adjusted HR 20.35, 95\% CI 16.23-25.53; reopening adjusted HR 0.38, 95\% CI $0.12-1.17)$.

We identified 15 people with a recent history of homelessness and 1053 community-dwelling people who required intensive care for COVID-19 (Table 2). People with a recent history of homelessness required intensive care only during the peak period. People with a recent history of homelessness were much more likely to require intensive care (unadjusted HR 33.75, 95\% CI 20.27-56.18) (Table 3). After adjustment, the hazard ratio remained significant (adjusted HR 10.20, 95\% CI 5.81-17.93).

Finally, we identified 10 people with a recent history of homelessness and 730 community-dwelling people who died within 21 days of a positive SARS-CoV-2 test result (Table 2). All deaths among people with a recent history of

\begin{tabular}{|lcc|}
\hline Table 2: Outcomes during follow-up & & \\
\hline Outcome & $\begin{array}{c}\text { No. of } \\
\text { patients }\end{array}$ & $\begin{array}{c}\text { Rate per 100 } \\
\text { person-years }\end{array}$ \\
\hline Tested for SARS-CoV-2 & & \\
\hline People with a recent history of homelessness & 8451 & 62.10 \\
\hline Community-dwelling people & 1266716 & 17.24 \\
\hline Tested positive for SARS-CoV-2 & 274 & 2.01 \\
\hline People with a recent history of homelessness & 28430 & 0.39 \\
\hline Community-dwelling people & 104 & 0.69 \\
\hline Admitted to hospital with COVID-19 & 3685 & 0.05 \\
\hline People with a recent history of homelessness & 15 & \\
\hline Community-dwelling people & 1053 & 0.10 \\
\hline Admitted to hospital with COVID-19 and required intensive care & & \\
\hline People with a recent history of homelessness & 10 & 0.01 \\
\hline Community-dwelling people & 730 & 0.01 \\
\hline Died within 21 d of positive SARS-CoV-2 test & & \\
\hline People with a recent history of homelessness & & \\
\hline Community-dwelling people & & \\
\hline Note: CovID-19 = coronavirus disease 2019, SARS-CoV-2 = severe acute respiratory syndrome coronavirus 2. \\
\hline
\end{tabular}


Table 3 (part 1 of 2): Adjusted and unadjusted hazard of outcomes related to COVID-19 (Jan. 23 to July 31, 2020) for people with a recent history of homelessness

\begin{tabular}{|c|c|c|c|c|c|}
\hline \multirow[b]{2}{*}{ Characteristic } & \multicolumn{5}{|c|}{ Hazard ratio $(95 \% \mathrm{Cl})$; outcome } \\
\hline & Tested* & Positivity† & $\begin{array}{c}\text { Hospital } \\
\text { admission }\end{array}$ & $\begin{array}{c}\text { Intensive } \\
\text { care§ }\end{array}$ & Deathๆ \\
\hline \multicolumn{6}{|l|}{ Unadjusted analysis } \\
\hline \multicolumn{6}{|l|}{$\begin{array}{l}\text { People with a recent history of homelessness } \\
\text { (Ref. = community-dwelling people) }\end{array}$} \\
\hline Preshutdown period: Jan. 23 to Mar. 13 & $\begin{array}{c}3.06 \\
(2.33-4.03)\end{array}$ & NR & NR & NR & NR \\
\hline Peak period: Mar. 14 to June 16 & $\begin{array}{c}5.06 \\
(4.93-5.19)\end{array}$ & $\begin{array}{c}5.07 \\
(4.94-5.20)\end{array}$ & $\begin{array}{c}65.12 \\
(53.45-79.34)\end{array}$ & $\begin{array}{c}33.75 \\
(20.27-56.18)\end{array}$ & $\begin{array}{c}7.64 \\
(4.09-14.24)\end{array}$ \\
\hline Reopening period: June 17 to July 31 & $\begin{array}{c}2.39 \\
(2.30-2.49)\end{array}$ & $\begin{array}{c}1.05 \\
(1.04-1.07)\end{array}$ & $\begin{array}{c}0.51 \\
(0.17-1.59)\end{array}$ & NR & NR \\
\hline \multicolumn{6}{|l|}{ Adjusted analysis } \\
\hline \multicolumn{6}{|l|}{$\begin{array}{l}\text { People with a recent history of homelessness } \\
\text { (Ref. = community-dwelling people) }\end{array}$} \\
\hline Preshutdown period: Jan. 23 to Mar. 13 & $\begin{array}{c}1.61 \\
(1.22-2.11)\end{array}$ & NR & NR & NR & NR \\
\hline Peak period: Mar. 14 to June 16 & $\begin{array}{c}2.95 \\
(2.88-3.03)\end{array}$ & $\begin{array}{c}3.66 \\
(3.22-4.16)\end{array}$ & $\begin{array}{c}20.35 \\
(16.23-25.53)\end{array}$ & $\begin{array}{c}10.20 \\
(5.81-17.93)\end{array}$ & $\begin{array}{c}5.73 \\
(3.01-10.91)\end{array}$ \\
\hline Reopening period: June 17 to July 31 & $\begin{array}{c}1.45 \\
(1.39-1.51)\end{array}$ & $\begin{array}{c}1.76 \\
(1.15-2.71)\end{array}$ & $\begin{array}{c}0.38 \\
(0.12-1.17)\end{array}$ & NR & NR \\
\hline \multicolumn{6}{|l|}{ Age group, yr (Ref. = youth [18-24 yr]) } \\
\hline Young adults (25-39) & $\begin{array}{c}2.02 \\
(2.01-2.03)\end{array}$ & $\begin{array}{c}2.05 \\
(1.97-2.13)\end{array}$ & $\begin{array}{c}3.47 \\
(2.70-4.46)\end{array}$ & $\begin{array}{c}4.39 \\
(2.37-8.14)\end{array}$ & $\begin{array}{c}4.99 \\
(0.56-44.53)\end{array}$ \\
\hline Older adults (40-64) & $\begin{array}{c}2.03 \\
(2.02-2.04)\end{array}$ & $\begin{array}{c}2.18 \\
(2.10-2.26)\end{array}$ & $\begin{array}{c}9.84 \\
(7.86-12.31)\end{array}$ & $\begin{array}{c}21.67 \\
(12.45-37.73)\end{array}$ & $\begin{array}{c}44.24 \\
(6.16-317.75)\end{array}$ \\
\hline Seniors $(\geq 65)$ & $\begin{array}{c}1.90 \\
(1.89-1.91)\end{array}$ & $\begin{array}{c}1.31 \\
(1.25-1.37)\end{array}$ & $\begin{array}{c}17.66 \\
(14.04-22.2)\end{array}$ & $\begin{array}{c}28.81 \\
(16.40-50.61)\end{array}$ & $\begin{array}{c}321.6 \\
(44.9-2299.9)\end{array}$ \\
\hline Sex (Ref. = female) & $\begin{array}{c}0.76 \\
(0.76-0.76)\end{array}$ & $\begin{array}{c}0.91 \\
(0.89-0.94)\end{array}$ & $\begin{array}{c}1.31 \\
(1.23-1.40)\end{array}$ & $\begin{array}{c}1.88 \\
(1.66-2.14)\end{array}$ & $\begin{array}{c}1.36 \\
(1.18-1.58)\end{array}$ \\
\hline Immigration status ${ }^{\star \star}$ (Ref. $=$ not an immigrant) & $\begin{array}{c}0.87 \\
(0.86-0.87)\end{array}$ & $\begin{array}{c}1.83 \\
(1.75-1.90)\end{array}$ & $\begin{array}{c}1.41 \\
(1.22-1.63)\end{array}$ & $\begin{array}{c}1.64 \\
(1.27-2.11)\end{array}$ & $\begin{array}{c}0.93 \\
(0.57-1.51)\end{array}$ \\
\hline \multicolumn{6}{|l|}{ 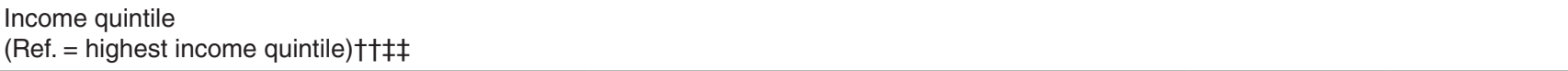 } \\
\hline 1 (lowest income) & $\begin{array}{c}0.96 \\
(0.95-0.96)\end{array}$ & $\begin{array}{c}2.01 \\
(1.93-2.09)\end{array}$ & $\begin{array}{c}2.02 \\
(1.82-2.25)\end{array}$ & $\begin{array}{c}1.93 \\
(1.57-2.36)\end{array}$ & $\begin{array}{c}1.64 \\
(1.30-2.08)\end{array}$ \\
\hline 2 & $\begin{array}{c}0.95 \\
(0.95-0.96)\end{array}$ & $\begin{array}{c}1.52 \\
(1.46-1.58)\end{array}$ & $\begin{array}{c}1.38 \\
(1.23-1.55)\end{array}$ & $\begin{array}{c}1.48 \\
(1.20-1.83)\end{array}$ & $\begin{array}{c}1.22 \\
(0.96-1.56)\end{array}$ \\
\hline 3 & $\begin{array}{c}0.94 \\
(0.94-0.95)\end{array}$ & $\begin{array}{c}1.42 \\
(1.36-1.48)\end{array}$ & $\begin{array}{c}1.33 \\
(1.18-1.49)\end{array}$ & $\begin{array}{c}1.27 \\
(1.02-1.58)\end{array}$ & $\begin{array}{c}1.24 \\
(0.97-1.58)\end{array}$ \\
\hline 4 & $\begin{array}{c}0.94 \\
(0.94-0.95)\end{array}$ & $\begin{array}{c}1.18 \\
(1.13-1.23)\end{array}$ & $\begin{array}{c}1.19 \\
(1.06-1.34)\end{array}$ & $\begin{array}{c}1.34 \\
(1.08-1.67)\end{array}$ & $\begin{array}{c}1.00 \\
(0.77-1.30)\end{array}$ \\
\hline \multicolumn{6}{|l|}{$\begin{array}{l}\text { Urbanicity } \\
\text { (Ref. = large CMA [> } 500000 \text { population]) }\end{array}$} \\
\hline $\begin{array}{l}\text { Small to medium-sized urban centres } \\
\text { (10 000-500 } 000 \text { population }\end{array}$ & $\begin{array}{c}1.13 \\
(1.13-1.14)\end{array}$ & $\begin{array}{c}0.48 \\
(0.47-0.50)\end{array}$ & $\begin{array}{c}0.44 \\
(0.41-0.48)\end{array}$ & $\begin{array}{c}0.45 \\
(0.39-0.53)\end{array}$ & $\begin{array}{c}0.51 \\
(0.43-0.61)\end{array}$ \\
\hline Areas with $<10000$ population & $\begin{array}{c}1.11 \\
(1.10-1.11)\end{array}$ & $\begin{array}{c}0.30 \\
(0.28-0.32)\end{array}$ & $\begin{array}{c}0.25 \\
(0.21-0.31)\end{array}$ & $\begin{array}{c}0.29 \\
(0.21-0.41)\end{array}$ & $\begin{array}{c}0.27 \\
(0.18-0.40)\end{array}$ \\
\hline Unknown & $\begin{array}{c}1.11 \\
(1.10-1.13)\end{array}$ & $\begin{array}{c}0.68 \\
(0.63-0.74)\end{array}$ & $\begin{array}{c}0.41 \\
(0.32-0.54)\end{array}$ & $\begin{array}{c}0.50 \\
(0.31-0.81)\end{array}$ & $\begin{array}{c}0.20 \\
(0.09-0.45)\end{array}$ \\
\hline
\end{tabular}




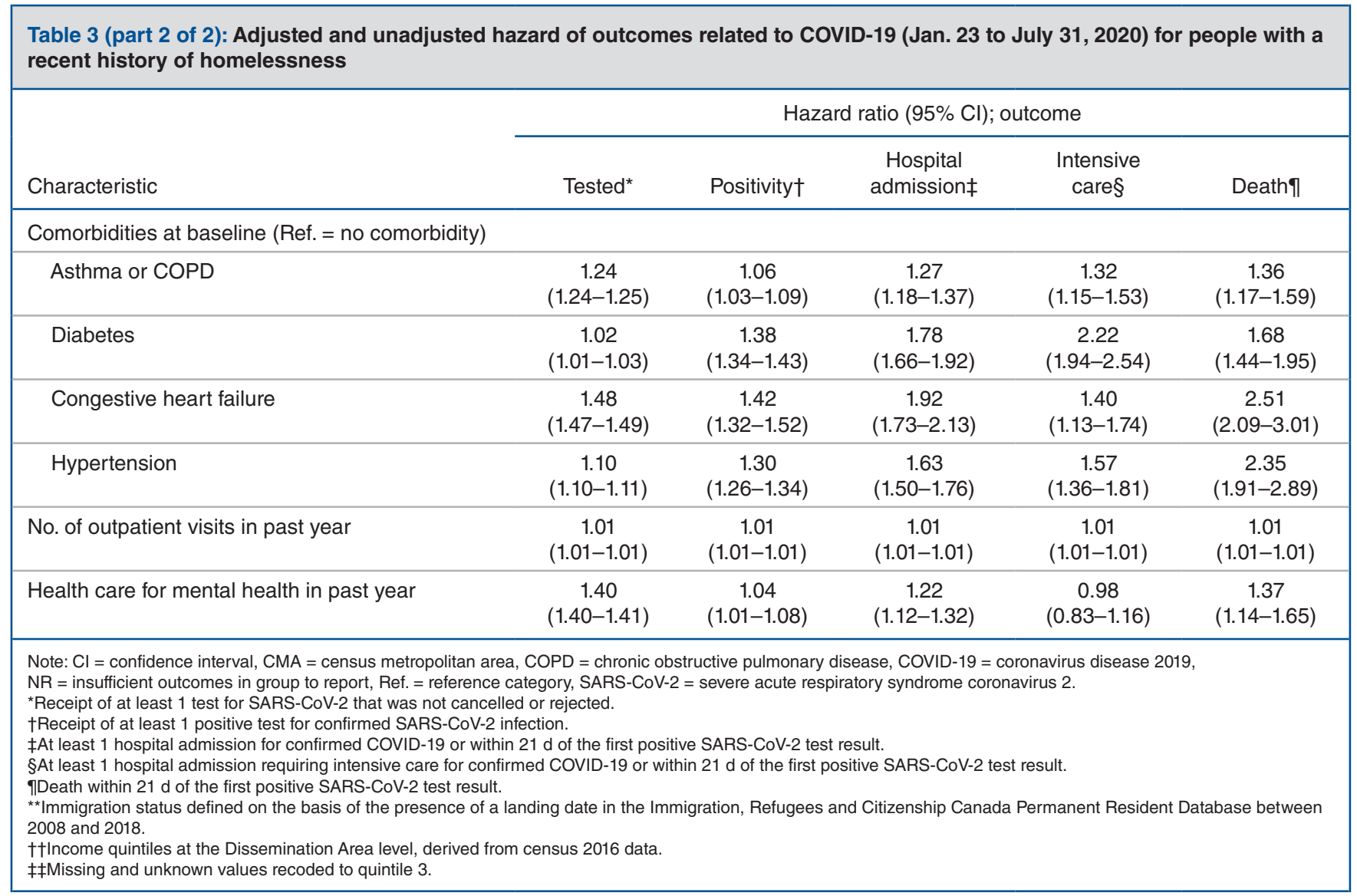

homelessness occurred during the peak period. The unadjusted hazard of death was 7.64 (95\% CI 4.09-14.24) (Table 3); after adjustment, the hazard was attenuated but remained significant (peak adjusted HR 5.73, 95\% CI 3.01-10.91).

\section{Interpretation}

We found that SARS-CoV-2 testing, test positivity and hospital admission, intensive care and mortality rates related to COVID-19 were all substantially higher among people with a recent history of homelessness than among the communitydwelling population, in particular during the peak period of Mar. 14 to June 16, 2020. During much of this period, Ontario's testing strategy focused on symptomatic people who had recently travelled out of country or who had preexisting risk factors (e.g., advanced age, comorbidities, homelessness). ${ }^{36-38}$ Disparate testing criteria probably resulted in an undercount of positive cases among the community-dwelling population, which may have inflated our observed positivity HR. Indeed, the adjusted hazard of positivity in the reopening period (when testing criteria were relaxed) was less than half that in the peak period.

Disparate testing criteria are less likely to have influenced complication-related estimates, as people with severe symptoms would have been more likely to receive care, leading to a test. During the height of the first wave of the COVID-19 pandemic, certain regions isolated people experiencing home- lessness who had COVID-19 in hospitals when alternative accommodations were unavailable, ${ }^{39,40}$ which may have inflated our HR for hospital admission during the peak period. However, the need for intensive care (also significantly higher among people with a recent history of homelessness) would not have been affected. Thus, policies may explain some but not all of the observed HR for hospital admission. Finally, although mortality rates depend on COVID-19 case identification, which was lower among the community-dwelling population, Ontario was able to meet needs for hospital care related to COVID-19 throughout the first wave, ${ }^{41}$ making it unlikely that large numbers of community-dwelling Ontarians failed to receive hospitalbased care before dying of COVID-19.

This study offers a population-level assessment of how COVID-19 has affected people with a recent history of homelessness. Several previous reports from the United States have detailed case rates among people experiencing homelessness in the shelters of certain cities, with positivity among those tested ranging between $2 \%$ and $18 \%, 9,42-44$ but they did not compare these rates with those in the general population. One report from Boston identified a cumulative case rate of $4.6 \%$ among people experiencing homelessness versus $0.19 \%$ in the general population over a 15 -day period. ${ }^{8}$ Another study from Brussels reported a cumulative case rate of $5.88 \%$ among people experiencing homelessness between March and May, with a hospital admission rate 3 times that of the general 
population. ${ }^{45}$ These 2 latter findings are not directly comparable with ours, however, because both reports relied on pointin-time counts (probably because of a lack of alternatives) to estimate the homeless population denominator, which have been shown to be unreliable when used for this purpose. ${ }^{46}$

\section{Limitations}

Our study relied on linked health administrative data, which follow the entire Ontario population eligible for OHIP coverage using encrypted identifiers; this allowed us to passively follow people, particularly hard-to-follow people with a recent history of homelessness, throughout the pandemic. This method also permits adjustment for important testing and outcome-related risk factors, such as previous health care usage (a proxy for propensity to seek out a test when symptomatic). However, OHIP eligibility does not extend to certain subgroups, in particular Indigenous people on reserves and certain refugee claimants who do not meet the refugee definition in the 1951 Geneva Convention. ${ }^{47}$ As both groups are overrepresented in Canada's homeless population, our counts of people with a recent history of homelessness are underestimates, particularly in the Greater Toronto Area, where refugees comprise one-third of shelter users. ${ }^{48}$ Our results could be affected if people experiencing homelessness who did not have coverage were disproportionately affected by COVID-19 relative to people with housing who did not have coverage. Thus, our results should be generalized only to people with Ontario health care coverage.

Our case definition of people with a recent history of homelessness also relies on interaction with the health care system, and previous work ${ }^{21}$ shows that a substantial number of people experiencing homelessness do not interact regularly with health care sources that record homelessness, leading to a relatively insensitive case definition. Thus, our cohort of people with a recent history of homelessness is probably smaller than the true Ontario population of people experiencing homelessness. However, because our numerator (people with a recent history of homelessness affected by COVID-19 outcomes) and denominator (population of people with a recent history of homelessness) were measured by the same method and the characteristics of our cohort of people with a recent history of homelessness (Table 1) were similar to those of people in other reports of homeless populations in Canada, ${ }^{20,21}$ we do not believe our undercount biased our rates, although rarer outcomes should be interpreted with caution. In particular, hospital admission rates were probably inflated as a result of policies leading to the quarantine of people experiencing homelessness who test positive.

A final weakness of health administrative data is the delay involved in fully receiving and verifying records. At the time of writing, it was impossible to report results with confidence beyond July 2020.

\section{Conclusion}

Legitimate concerns exist about the potential impact of the COVID-19 pandemic on people experiencing homelessness. In Ontario, we found that people with a recent history of homelessness were more likely to test positive for SARS-CoV-2 and substantially more likely to experience complications related to COVID-19 than the community-dwelling population. People experiencing homelessness should continue to be considered particularly vulnerable to COVID-19. Further work will be needed to update these findings as the pandemic progresses and to assess the effectiveness of sheltering and other countermeasures used by many Ontario cities that are meant to mitigate this population's vulnerability to outbreaks.

\section{References}

1. Patton J. Coronavirus: advocates threaten legal action if Toronto doesn't step up aide for homeless population. Global News 2020 Apr. 21. Available: https:// globalnews.ca/news/6847669/coronavirus-toronto-homeless-aid/ (accessed 2020 Aug. 5).

2. Volkow ND. Collision of the COVID-19 and addiction epidemics. Ann Intern Med 2020;173:61-2.

3. Tsai J, Wilson M. COVID-19: a potential public health problem for homeless populations. Lancet Public Health 2020;5:e186-7.

4. Culhane D, Treglia D, Steif K, et al. Estimated emergency and observational/ quarantine capacity need for the US homeless population related to COVID-19 exposure by county; projected hospitalizations, intensive care units and mortality. Berkeley (CA): Bepress; 2020.

5. Lima NNR, de Souza RI, Feitosa PWG, et al. People experiencing homelessness: their potential exposure to COVID-19. Psychiatry Res 2020;288:112945.

6. Perri M, Dosani N, Hwang SW. COVID-19 and people experiencing homelessness: challenges and mitigation strategies. CMA7 2020;192:E716-9.

7. Fazel S, Geddes JR, Kushel M. The health of homeless people in highincome countries: descriptive epidemiology, health consequences, and clinical and policy recommendations. Lancet 2014;384:1529-40.

8. Casey L. COVID-19 spreading among Toronto's homeless, with 30 cases reported. CBC New Toronto 2020 Apr. 14. Available: www.cbc.ca/news/canada/ toronto/homeless-population-toronto-covid-19-1.5532300 (accessed 2020 Aug. 5).

9. Baggett TP, Keyes H, Sporn N, et al. Prevalence of SARS-CoV-2 infection in residents of a large homeless shelter in Boston. 7AMA 2020;323:2191-2.

10. Mosites E, Parker EM, Clarke KE, et al.; COVID-19 Homelessness Team. Assessment of SARS-CoV-2 infection prevalence in homeless shelters - four U.S. cities, March 27-April 15, 2020. MMWR Morb Mortal Wkly Rep 2020;69:521-2.

11. Yu A. "People are sleeping in the streets or ravines because shelters are unsafe": This doctor is helping restructure homeless shelters during the Covid crisis. Toronto Life 2020 Apr. 15. Available: https://torontolife.com/ city/people-are-sleeping-in-the-streets-or-ravines-because-shelters-are-unsafe -this-doctor-is-helping-restructure-homeless-shelters-during-the-covid-crisis/ (accessed 2020 Aug. 5).

12. Hanson H. Ottawa will consider buying empty hotels to house the city's homeless people. Narcity 2020 Apr. 21. Available: www.narcity.com/news/ca/ on/ottawa/hotel-for-homeless-people-in-ottawa-is-being-considered-by-the -city (accessed 2020 Aug. 5).

13. D'Ávino C. Sault motel to offer emergency self-isolation rooms for city's less-fortunate. CTV News Northern Ontario 2020 Apr. 5. Available: https:// northernontario.ctvnews.ca/sault-motel-to-offer-emergency-self-isolation -rooms-for-city-s-less-fortunate-1.4883278 (accessed 2020 Aug. 5).

14. Bogdan S. City of London moving homeless into motels to combat spread of COVID-19. Global News 2020 Apr. 1, updated 2020 Apr. 4. Available: https:// globalnews.ca/news/6764303/coronavirus-london-ont-homeless-motels/ (accessed 2020 Aug. 5).

15. LaFleche G. Homeless shelters adapt to pandemic, prepare to house infected clients. Niagara Falls Review 2020 Mar. 18, updated 2020 June 2. Available: www.niagarafallsreview.ca/news-story/9910529-homeless-shelters-adapt-to -pandemic-prepare-to-house-infected-clients/ (accessed 2020 Aug. 5).

16. Connor B. Sudbury's homeless shelter temporarily relocating to hotel. CTV News Northern Ontario 2020 Apr. 6. Available: https://northernontario. ctvnews.ca/sudbury-s-homeless-shelter-temporarily-relocating-to-hotel-1. 4884916 (accessed 2020 Aug. 5)

17. Nielsen K. Coronavirus: Radisson will be isolation shelter for Waterloo homeless who contract COVID-19. Global News 2020 Mar. 23, updated 2020 Mar. 25. Available: https://globalnews.ca/news/6719914/coronavirus-waterloo -radisson-homeless/ (accessed 2020 Aug. 5).

18. La Grassa J. FirstOntario Centre will become a shelter for Hamilton's homeless during COVID-19. CBC News 2020 Apr. 9. Available: www.cbc.ca/news/canada/ hamilton/homeless-population-shelters-covid-19-hamilton-1.5527529 (accessed 2020 Aug. 5).

19. Johnstone H. City opens arena to give homeless men some space. CBC News 2020 Apr. 29. Available: www.cbc.ca/news/canada/ottawa/physical-distancing -centre-ottawa-homeless-1.5549111 (accessed 2020 Aug. 5). 
20. Gaetz S, Dej E, Richter T, et al. The state of homelessness in Canada 2016. Toronto: Canadian Observatory on Homelessness Press; 2016.

21. Richard L, Hwang SW, Forchuk C, et al. Validation study of health administrative data algorithms to identify individuals experiencing homelessness and estimate population prevalence of homelessness in Ontario, Canada. BMF Open 2019;9:e030221.

22. ICES [main page]. Available: www.ices.on.ca (accessed 2020 Aug. 5).

23. Benchimol EI, Smeeth L, Guttmann A, et al.; RECORD Working Committee. The REporting of studies Conducted using Observational Routinelycollected health Data (RECORD) statement. PLoS Med 2015;12:e1001885.

24. Ontario confirms first case of Wuhan novel coronavirus [news release]. Toronto: Ministry of Health and Long-Term Care; 2020 Jan. 25. Available: https://news.ontario.ca/mohltc/en/2020/01/ontario-confirms-first-case-of -wuhan-novel-coronavirus.html (accessed 2020 Aug. 5).

25. Data quality documentation: Discharge Abstract Database - current-year information 2018-2019. Ottawa: Canadian Institute for Health Information; 2019.

26. Gershon AS, Wang C, Guan J, et al. Identifying individuals with physician diagnosed COPD in health administrative databases. COPD 2009;6:388-94.

27. Gershon AS, Wang C, Guan J, et al. Identifying patients with physiciandiagnosed asthma in health administrative databases. Can Respir 7 2009; 16:183-8.

28. Hux JE, Ivis F, Flintoft V, et al. Diabetes in Ontario: determination of prevalence and incidence using a validated administrative data algorithm. Diabetes Care 2002;25:512-6.

29. Schultz SE, Rothwell DM, Chen Z, et al. Identifying cases of congestive heart failure from administrative data: a validation study using primary care patient records. Chronic Dis Inj Can 2013;33:160-6.

30. Tu K, Chen Z, Lipscombe LL, et al.; Canadian Hypertension Education Program Outcomes Research Taskforce. Prevalence and incidence of hypertension from 1995 to 2005: a population-based study. CMA7 2008;178: 1429-35.

31. Ontario enacts declaration of emergency to protect the public: significantly enhanced measures will help contain spread of COVID-19 [news release]. Toronto: Ministry of Health and Long-Term Care; 2020 Mar. 17 Available: https://news.ontario.ca/en/release/56356/ontario-enacts-declaration -of-emergency-to-protect-the-public (accessed 2020 Aug. 5).

32. ICD-10-CA coding direction for suspected COVID-19 cases. Ottawa: Canadian Institute for Health Information; 2020. Available: www.cihi.ca/en/ bulletin/icd-10-ca-coding-direction-for-suspected-covid-19-cases (accessed 2020 Aug. 5).

33. Perri M, Dosani N, Hwang SW. COVID-19 and people experiencing homelessness: challenges and mitigation strategies. CMA7 2020;192:E716-9.

34. Austin PC. Using the standardized difference to compare the prevalence of a binary variable between two groups in observational research. Commun Stat Simul Comput 2009;38:1228-34

35. Kleinbaum DG, Klein M. Survival analysis: a self-learning text. 3rd ed. New York: Springer Publishing; 2011.

36. COVID-19 guidance: homeless shelters. Toronto: Registered Nurses' Association of Ontario; 2020. Available: https://myrnao.ca/sites/default/files/attached_ files/Homeless\%20Shelters\%20COVID-19\%20Guidance\%20Document\%20 -\%20March\%2031_2020_final_for\%20translation.pdf (accessed 2020 June 8).

37. City of Toronto COVID-19 response for people experiencing homelessness. Toronto: City of Toronto; 2020. Available: www.toronto.ca/news/city-of -toronto-covid-19-response-for-people-experiencing-homelessness/ (accessed 2020 June 8 ).

38. COVID-19 testing criteria. Ottawa: Ottawa Public Health. Available: www. ottawapublichealth.ca/en/shared-content/covid-19-testing-criteria.aspx (accessed 2020 June 8).

39. Bingley M. Coronavirus: Toronto's homeless COVID-19 patients sent to hospital due to lack of recovery site. Global News 2020 Apr. 10. Available: https:// globalnews.ca/news/6806485/coronavirus-toronto-homeless-hospitals-covid -19-recovery-site/ (accessed 2020 June 8).

40. Snider C. How COVID-19 cases among the homeless overwhelm St. Mike's hospital. Toronto Star 2020 June 17. Available: www.thestar.com/opinion/ contributors/2020/06/17/how-covid-19-cases-among-the-homeless-overwhelm -st-mikes-hospital.html (accessed 2020 Aug. 5).

41. Ontario Health Sector: a preliminary review of the impact of the COVID-19 outbreak on hospital capacity. Toronto: Financial Accountability Office of Ontario; 2020. Available: www.fao-on.org/en/Blog/Publications/health-2020 (accessed 2020 June 8)

42. Tobolowsky FA, Gonzales E, Self JL, et al. COVID-19 outbreak among three affiliated homeless service sites - King County, Washington, 2020. MMWR Morb Mortal Wkly Rep 2020;69:523-6.
43. Yoon JC, Montgomery MP, Buff AM, et al. COVID-19 prevalence among people experiencing homelessness and homelessness service staff during early community transmission in Atlanta, Georgia, April-May 2020. Clin Infect Dis 2020 Sept. 8 [Epub ahead of print]. doi: 10.1093/cid/ciaal340.

44. Rogers JH, Link AC, McCulloch D, et al. Characteristics of COVID-19 in homeless shelters: a community-based surveillance study. Ann Intern Med 2020 Sept. 15 [Epub ahead of print]. doi: 10.7326/M20-3799.

45. Schrooyen L, Delforge M, Lebout F, et al. Homeless people hospitalized with COVID-19 in Brussels. Clin Microbiol Infect 2020 Aug. 7 [Epub ahead of print]. doi: 10.1016/j.cmi.2020.08.002.

46. 5 myths about PIT counts. Washington (DC): National Alliance to End Homelessness; 2015. Available: www.homelesshub.ca/resource/5-myths -about-pit-counts (accessed 2020 Aug. 5).

47. Apply for OHIP and get a health card. Toronto: Government of Ontario. Available: www.ontario.ca/page/apply-ohip-and-get-health-card (accessed 2020 Aug. 5).

48. Refugees \& asylum claimants experiencing homelessness in the City of Toronto. Toronto: City of Toronto; 2019. Available: www.toronto.ca/news/ refugees-asylum-claimants-experiencing-homelessness-in-the-city-of-toronto/ (accessed 2020 Aug. 5).

Affiliations: ICES Western (Richard, Shariff); Western University (Booth, Clemens, Forchuk), London, Ont.; Alliance for Healthier Communities (Rayner), Toronto, Ont.

Contributors: Lucie Richard and Salimah Shariff conceived of the study. All authors contributed to the study design. Lucie Richard conducted the analysis of the data. All authors interpreted the results. Lucie Richard drafted the manuscript, which all authors revised. All authors approved the final version to be published and agreed to be accountable for all aspects of the work.

Funding: This study was supported by ICES Western.

Content licence: This is an Open Access article distributed in accordance with the terms of the Creative Commons Attribution (CC BY-NC-ND 4.0) licence, which permits use, distribution and reproduction in any medium, provided that the original publication is properly cited, the use is noncommercial (i.e., research or educational use), and no modifications or adaptations are made. See: https:// creativecommons.org/licenses/by-nc-nd/4.0/

Data sharing: The data set from this study is held securely in coded form at ICES. While data-sharing agreements prohibit ICES from making the data set publicly available, access may be granted to those who meet prespecified criteria for confidential access, available at www.ices.on.ca/DAS. The full data-set creation plan and underlying analytic code are available from the authors upon request, with the understanding that the computer programs may rely upon coding templates or macros that are unique to ICES and therefore either are inaccessible or may require modification.

Acknowledgement: Information in the Immigration, Refugees and Citizenship Canada Permanent Resident Database was provided by Immigration, Refugees and Citizenship Canada.

Disclaimer: This study was conducted and supported by ICES Western, which receives core funding from the Academic Medical Organization of Southwestern Ontario, the Schulich School of Medicine and Dentistry, Western University, and the Lawson Health Research Institute. ICES is funded by an annual grant from the Ontario Ministry of Health. The opinions, results and conclusions reported are those of the authors and are independent from the funding sources. No endorsement by ICES or the funding agencies is intended or should be inferred. Parts of this material are based on data and information compiled and provided by the Canadian Institute for Health Information (CIHI). However, the analyses, conclusions, opinions and statements expressed in the material are those of the authors and not necessarily those of CIHI.

Supplemental information: For reviewer comments and the original submission of this manuscript, please see www.cmajopen.ca/content/9/1/ E1/suppl/DC1. 